\title{
Clinical Outcomes of Transcatheter vs Surgical Aortic Valve Replacement in Patients With Chronic Liver Disease: A Systematic Review and Metaanalysis
}

\author{
Paul Ndunda, MD, ${ }^{1}$ Sachin Srinivasan, MD, ${ }^{1}$ Mohinder Vindhyal, MD, ${ }^{1}$ Tabitha Muutu, MD, ${ }^{1}$ Rachel Vukas, MA, MLS, ${ }^{2}$ \\ Zaher Fanari, MD ${ }^{1,3}$ \\ ${ }^{1}$ Department of Internal Medicine, University of Kansas School of Medicine-Wichita, Wichita, KS ${ }^{2}$ A. R. Dykes Library, Research \& Learning, \\ University of Kansas Medical Center, Kansas City, KS ${ }^{3}$ Heartland Cardiology/Wesley Medical Center, University of Kansas School of \\ Medicine-Wichita, Wichita, KS
}

\begin{abstract}
Background: Chronic liver disease increases cardiac surgical risk, with 30-day mortality ranging from $9 \%$ to $52 \%$ in patients with Child-Pugh class A and C, respectively. Data comparing the outcomes of transcatheter aortic valve replacement (TAVR) and surgical aortic valve replacement (SAVR) in patients with liver disease are limited.

Methods: We searched PubMed, Cochrane Library, Web of Science, and Google Scholar for relevant studies and assessed risk of bias using the Risk of Bias in Non-Randomized Studies - of Interventions (ROBINS-I) Cochrane Collaboration tool.

Results: Five observational studies with 359 TAVR and 1,872 SAVR patients were included in the analysis. Overall, patients undergoing TAVR had a statistically insignificant lower rate of in-hospital mortality (7.2\% vs $18.1 \%$; odds ratio [OR] 0.67; $95 \%$ confidence interval $\left.[\mathrm{Cl}] 0.25,1.82 ; \mathrm{I}^{2}=61 \%\right)$ than patients receiving SAVR. In propensity score-matched cohorts, patients undergoing TAVR had lower rates of in-hospital mortality (7.3\% vs $13.2 \%$; OR $\left.0.51 ; 95 \% \mathrm{Cl} 0.27,0.98 ; \mathrm{I}^{2}=13 \%\right)$, blood transfusion $(27.4 \%$ vs $51.1 \%$; OR 0.36 ; $95 \% \mathrm{Cl} 0.21,0.60 ; \mathrm{I}^{2}=31 \%$ ), and hospital length of stay (10.9 vs 15.7 days; mean difference $-6.32 ; 95 \% \mathrm{Cl}-10.28,-2.36 ; \mathrm{I}^{2}=83 \%$ ) than patients having SAVR. No significant differences between the 2 interventions were detected in the proportion of patients discharged home (65.3\% vs 53.9\%; OR 1.3; 95\% Cl 0.56, 3.05; $\left.\mathrm{I}^{2}=67 \%\right)$, acute kidney injury (10.4\% vs $17.1 \%$; OR 0.55; $95 \% \mathrm{Cl} 0.29,1.07$; $\left.\mathrm{I}^{2}=0 \%\right)$, or mean cost of hospitalization $\left(\$ 250,386\right.$ vs $\$ 257,464$; standardized mean difference $\left.-0.07 ; 95 \% \mathrm{Cl}-0.29,0.14 ; \mathrm{I}^{2}=0 \%\right)$.
\end{abstract}

Conclusion: In patients with chronic liver disease, TAVR may be associated with lower rates of in-hospital mortality, blood transfusion, and hospital length of stay compared with SAVR.

Keywords: Aortic valve stenosis, cirrhosis, end stage liver disease, heart valve diseases, liver diseases, transcatheter aortic valve replacement, treatment outcome

Address correspondence to Paul Ndunda, MD, Department of Internal Medicine, University of Kansas School of Medicine-Wichita, $1010 \mathrm{~N}$ Kansas Street, Wichita, KS 67214. Tel: (316) 258-3350. Email: muutu@live.com

\section{INTRODUCTION}

The surgical morbidity and mortality of patients with advanced chronic liver disease undergoing heart surgery remain high, ${ }^{1,2}$ particularly among patients with cirrhosis Child-Pugh class $\mathrm{B}$ and $\mathrm{C}$ undergoing cardiopulmonary bypass. ${ }^{1,2}$ The 30-day mortality risk following cardiac surgery is $9 \%$ in patients with liver cirrhosis Child-Pugh class A, $37.7 \%$ in patients with class $B$, and $52 \%$ in patients with class C. ${ }^{3}$ Patients with chronic liver disease have pathophysiologic changes that increase their risk of hemorrhage and organ failure. Also, extracorporeal circulation initiates pathophysiologic processes that may impair coagulation and organ function in patients with chronic liver disease. ${ }^{1,2}$ Among patients with severe aortic stenosis, $2 \%$ to $5 \%$ have liver cirrhosis. ${ }^{4-8}$ With an increasing prevalence of cirrhosis and an aging population in the United States, the burden of these comorbidities is likely to rise. ${ }^{9}$ The valvular surgical risk stratification tools commonly used (Society of Thoracic Surgeons [STS] Predicted Risk of Mortality and the European System for Cardiac Operative Risk Evaluation [EuroSCORE II] models) do not include liver disease in their risk stratification. ${ }^{10-12}$ Data comparing surgical aortic valve replacement (SAVR) and transcatheter aortic valve replacement (TAVR) in patients with cirrhosis are limited because these patients are usually excluded from clinical trials. The need exists for a systematic review of available evidence and a metaanalysis to help inform decision making in this patient population. Consequently, the objective of this systematic review was to compare the clinical outcomes of patients with chronic liver disease undergoing TAVR and SAVR. 


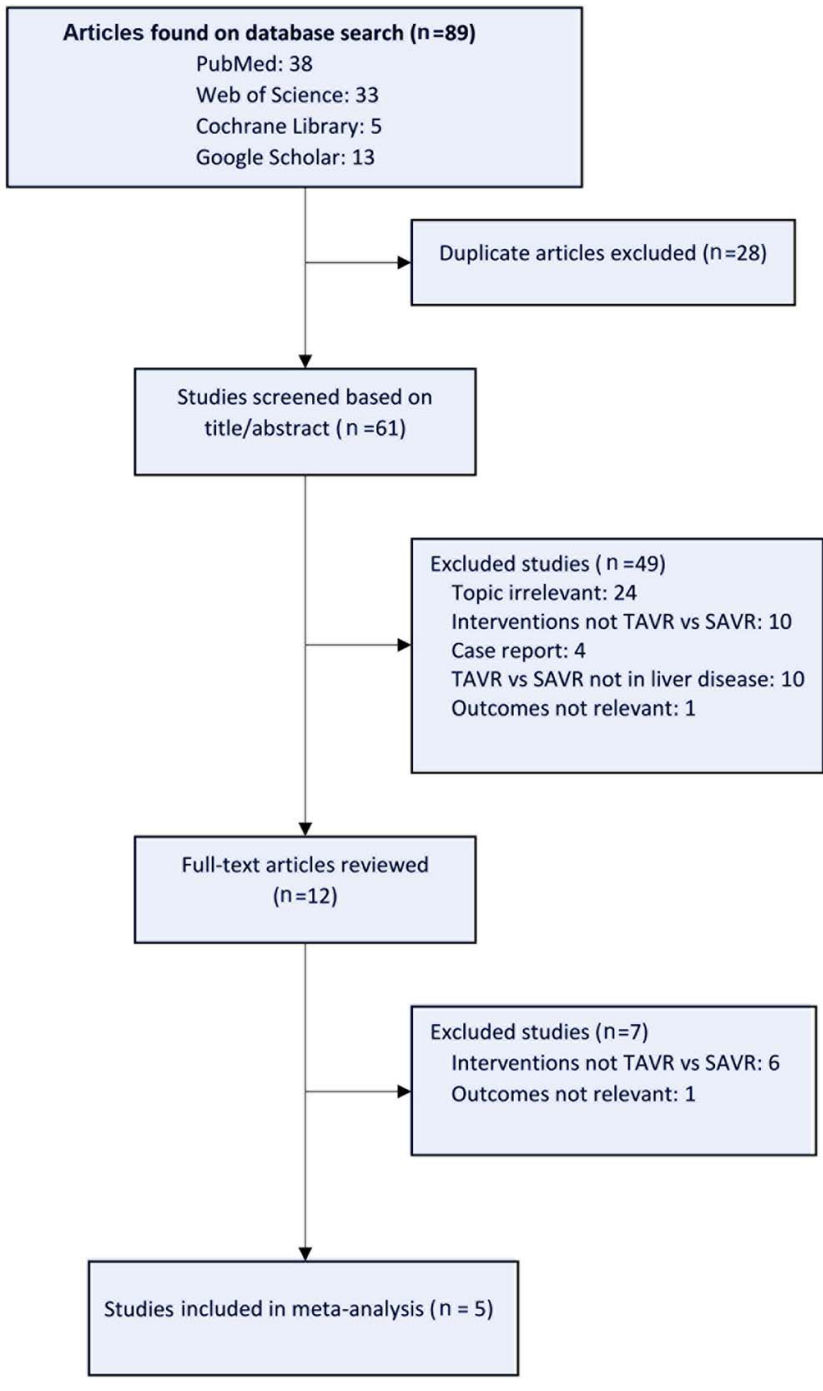

Figure 1. Summary of literature search and selection. SAVR, surgical aortic valve replacement; TAVR, transcatheter aortic valve replacement.

\section{METHODS}

This review followed the PRISMA (Preferred Reporting Items for Systematic Reviews and Meta-Analyses) recommendations in our protocol, data analysis, and reporting. ${ }^{13}$

A medical librarian (R.V.) searched the following databases for relevant studies: the Cochrane Library, PubMed, Google
Scholar, and the Web of Science from 2009 through May 21,2018 , with no language restrictions. We used medical subject heading terms where available and various combinations of keywords to represent the following concepts: "cirrhosis," "chronic liver disease," "transcatheter aortic valve replacement," "transcatheter aortic valve implantation," "surgical aortic valve replacement," and "surgical aortic valve implantation." We also searched clinicaltrials.gov (May 21, 2018) for ongoing and completed studies.

Studies were considered if they were randomized controlled trials or controlled observational studies and compared TAVR with SAVR in patients with chronic liver disease. We included studies that reported one or more of the following clinical outcomes: mortality, major or life-threatening bleeding, need for blood transfusion, acute kidney injury, length of hospital stay, proportion of patients discharged home, and cost of hospitalization. Two authors (P.N. and S.S.) independently assessed study eligibility, and differences were resolved through discussion or by a third author (Z.F.) when necessary.

Two authors (P.N. and S.S.) independently reviewed all the articles and summarized the study characteristics in a data extraction table adapted from the Cochrane Collaboration data extraction template. The data collected were study design, sample size, patient characteristics and clinical outcomes (death, blood transfusion, periprocedural length of stay, proportion of patients discharged home, acute kidney injury, and cost of hospitalization). The Cochrane Collaboration Risk of Bias in Non-Randomized Studies - of Interventions (ROBINS-I) tool was used to assess the risk of bias. ${ }^{14}$

We conducted a qualitative and a quantitative analysis. Effect sizes are presented using the Mantel-Haenszel odds ratio $(\mathrm{OR})$, mean difference, or standardized mean difference with their respective 95\% confidence intervals $(\mathrm{Cls})$. The Higgins I-squared $\left(\mathrm{I}^{2}\right)$ statistic was used to measure heterogeneity. We used a random effects model in all analyses with heterogeneity $>25 \%$. Sensitivity analyses were done by removing one study at a time. RevMan v.5.3 was used for metaanalysis.

\section{RESULTS}

\section{Search Results and Patient Characteristics}

The database search retrieved a total of 89 publications (Figure 1). Five observational studies met the eligibility criteria and were included in the systematic review and metaanalysis. ${ }^{2,4,15-17}$ Table 1 summarizes the characteristics of the included studies. These studies included a

Table 1. Characteristics of Studies Included in the Metaanalysis

\begin{tabular}{|c|c|c|c|c|c|c|}
\hline Study & Study Type & Study Population & Total Patients, $\mathbf{n}$ & TAVR, $\mathbf{n}$ & SAVR, $n$ & ROBINS-I \\
\hline Greason et al, ${ }^{2} 2013$ & Observational & Cirrhosis & 18 & 6 & 12 & Moderate \\
\hline Thakkar et al, ${ }^{17} 2016$ & Observational & Cirrhosis & 129 & 36 & 93 & Moderate \\
\hline Schill et al, ${ }^{16} 2017$ & Observational & Chronic liver disease & 35 & 17 & 18 & Unclear \\
\hline Alqahtani et al, ${ }^{15} 2017$ & Observational & Cirrhosis & 1,766 & 174 & 1,592 & Moderate \\
\hline Dhoble et al, ${ }^{4} 2018$ & Observational & Cirrhosis & 283 & 126 & 157 & Moderate \\
\hline
\end{tabular}

ROBINS-I, Risk of Bias in Non-Randomized Studies - of Interventions; SAVR, surgical aortic valve replacement; TAVR, transcatheter aortic valve replacement. 
Table 2. Patient Clinical Characteristics, Unmatched Cohort

\begin{tabular}{|c|c|c|c|c|c|c|c|c|c|c|}
\hline \multirow[b]{2}{*}{ Characteristic } & \multicolumn{2}{|c|}{ Alqahtani, et al ${ }^{15 a}$} & \multicolumn{2}{|c|}{ Dhoble, et $a^{4 a, b}$} & \multicolumn{2}{|c|}{ Thakkar, et al ${ }^{17 a, b}$} & \multicolumn{2}{|c|}{ Greason, et $\mathrm{al}^{2}$} & \multicolumn{2}{|c|}{ Schill, et al ${ }^{16}$} \\
\hline & $\begin{array}{c}\text { TAVR } \\
n=174\end{array}$ & $\begin{array}{c}\text { SAVR } \\
n=1,592\end{array}$ & $\begin{array}{c}\text { TAVR } \\
n=126\end{array}$ & $\begin{array}{c}\text { SAVR } \\
n=157\end{array}$ & $\begin{array}{l}\text { TAVR } \\
n=36\end{array}$ & $\begin{array}{l}\text { SAVR } \\
n=93\end{array}$ & $\begin{array}{l}\text { TAVR } \\
n=6\end{array}$ & $\begin{array}{l}\text { SAVR } \\
n=12\end{array}$ & $\begin{array}{l}\text { TAVR } \\
n=17\end{array}$ & $\begin{array}{l}\text { SAVR } \\
n=18\end{array}$ \\
\hline Mean age, years & 72 & 64 & 71.7 & 65.3 & 73.4 & 66 & 76 & 68 & 73.8 & 55.1 \\
\hline Male & $108(62.1)$ & $1,041(65.4)$ & $(58.7)$ & $(65.6)$ & $(77.8)$ & $(67.7)$ & $5(83)$ & $10(83)$ & $12(70.6)$ & $12(66.7)$ \\
\hline Mean MELD score & NA & NA & NA & NA & NA & NA & 9 & 10 & 10.7 & 11.8 \\
\hline $\begin{array}{l}\text { Chronic kidney } \\
\text { disease }\end{array}$ & $77(44.3)$ & $369(23.2)$ & NA & NA & NA & NA & NA & NA & $1(5.9)$ & $4(22.2)$ \\
\hline Hypertension & $124(71.3)$ & $785(49.3)$ & NA & NA & $(69.4)$ & $(66.7)$ & NA & NA & $15(88.2)$ & $11(61.1)$ \\
\hline Diabetes & $88(50.6)$ & $447(28.1)$ & $(60.3)$ & $(47.1)$ & $(58.3)$ & $(47.3)$ & $3(50)$ & $3(25)$ & $11(64.7)$ & $4(22.2)$ \\
\hline $\begin{array}{l}\text { Congestive heart } \\
\text { failure }\end{array}$ & $21(12.1)$ & $134(8.4)$ & $(70.6)$ & $(49.0)$ & 0 & (4.3) & $6(100)^{c}$ & $6(50)^{c}$ & $15(88.2)$ & $10(55.6)$ \\
\hline $\begin{array}{l}\text { Peripheral artery } \\
\text { disease }\end{array}$ & $48(27.6)$ & $271(17.0)$ & $(21.4)$ & $(10.2)$ & $(19.4)$ & $(14.0)$ & $4(66.7)$ & $2(16.7)$ & $7(41.2)$ & $1(5.6)$ \\
\hline $\begin{array}{l}\text { Atrial fibrillation } \\
\text { or flutter }\end{array}$ & $63(36.2)$ & $659(41.4)$ & NA & NA & NA & NA & NA & NA & NA & NA \\
\hline $\begin{array}{l}\text { Chronic lung } \\
\text { disease }\end{array}$ & 55 (31.6) & $379(23.8)$ & NA & NA & $(27.8)$ & $(32.3)$ & $3(50)$ & $3(25)$ & $8(47.1)$ & 7 (38.9) \\
\hline
\end{tabular}

total of 2,231 patients, with 359 and 1,872 patients assigned to the TAVR and SAVR arms, respectively. Table 2 summarizes the characteristics of all patients, and Table 3 provides the characteristics of the patients in the propensity score- matched cohorts. In the 5 studies identified for this metaanalysis, bleeding events were either not reported (Dhoble et $\mathrm{al}^{4}$ and Alqahtani et $\mathrm{al}^{15}$ ) or the reporting was too clinically heterogeneous to be pooled. We therefore did not conduct

Table 3. Patient Clinical Characteristics, Propensity Score-Matched Cohorts

\begin{tabular}{|c|c|c|c|c|c|c|}
\hline \multirow[b]{2}{*}{ Characteristic } & \multicolumn{2}{|c|}{ Alqahtani, et al ${ }^{15 a}$} & \multicolumn{2}{|c|}{ Dhoble, et $\mathrm{al}^{4 \mathrm{a}}$} & \multicolumn{2}{|c|}{ Thakkar, et al ${ }^{17 a}$} \\
\hline & $\begin{array}{c}\text { TAVR } \\
n=134\end{array}$ & $\begin{array}{c}\text { SAVR } \\
n=134\end{array}$ & $\begin{array}{l}\text { TAVR } \\
n=55\end{array}$ & $\begin{array}{l}\text { SAVR } \\
n=55\end{array}$ & $\begin{array}{l}\text { TAVR } \\
n=30\end{array}$ & $\begin{array}{l}\text { SAVR } \\
n=30 \\
\end{array}$ \\
\hline Mean age, years & 71 & 71 & 67.2 & 67 & 71.7 & 70.5 \\
\hline Male & $84(62.7)$ & $79(59)$ & $(65.5)$ & $(65.5)$ & $(73.3)$ & $(66.7)$ \\
\hline Mean MELD score & NA & NA & NA & NA & NA & NA \\
\hline Chronic kidney disease & $52(38.8)$ & $53(39.6)$ & NA & NA & NA & NA \\
\hline Hypertension & $93(69.4)$ & $93(69.4)$ & NA & NA & $(66.7)$ & $(73.3)$ \\
\hline Diabetes & $64(47.8)$ & $59(44.0)$ & $(58.2)$ & $(54.4)$ & $(53.3)$ & $(53.3)$ \\
\hline Congestive heart failure & $17(12.7)$ & $13(9.7)$ & $(56.4)$ & $(54.5)$ & 0 & $(13.3)$ \\
\hline Coronary artery disease & $55(41.0)$ & $56(41.8)$ & $(61.8)$ & $(43.6)$ & NA & NA \\
\hline Peripheral artery disease & $31(23.1)$ & $28(20.9)$ & $(21.8)$ & $(10.9)$ & $(20.0)$ & $(10.0)$ \\
\hline Atrial fibrillation or flutter & $54(40.3)$ & $57(42.5)$ & NA & NA & NA & NA \\
\hline Chronic lung disease & $38(28.4)$ & $40(29.9)$ & NA & NA & $(23.3)$ & $(43.3)$ \\
\hline
\end{tabular}

a Patient numbers $(n)$ not provided in the article for the characteristics.

Note: Data are presented as $\mathrm{n}(\%)$ or as (\%) unless otherwise indicated.

MELD, Model for End-Stage Liver Disease; SAVR, surgical aortic valve replacement; TAVR, transcatheter aortic valve replacement. 


\section{A: In-Hospital Mortality, All Patients}

\begin{tabular}{|c|c|c|c|c|c|c|c|c|c|c|}
\hline Study or Subgroup & \multicolumn{2}{|c|}{ TAVR } & SAVR & Rotal & Weight & $\begin{array}{c}\text { Odds Ratio } \\
\mathrm{M} \cdot \mathrm{H}, \text { Random, } 95 \% \mathrm{Cl}\end{array}$ & \multicolumn{4}{|c|}{$\begin{array}{c}\text { Odds Ratio } \\
\mathrm{M} \cdot \mathrm{H}, \text { Random, } 95 \% \mathrm{Cl}\end{array}$} \\
\hline Alqahtani 2017 & 14 & 174 & 321 & 1592 & $34.9 \%$ & $0.35[0.20,0.61]$ & & $\rightarrow$ & & \\
\hline Ohoble 2018 & 9 & 126 & 7 & 157 & $27.9 \%$ & $1.65[0.60 .4 .56]$ & & & & \\
\hline Greason 2013 & 0 & 6 & 2 & 12 & $7.8 \%$ & $0.32[0.01,7.85]$ & & & & \\
\hline Schill 2017 & 0 & 17 & 3 & 18 & $8.4 \%$ & $0.13[0.01,2.65]$ & & & & \\
\hline Thakkar 2016 & 3 & 36 & 5 & 93 & $21.0 \%$ & $1.60[0.36,7.07]$ & & & & \\
\hline Total $(95 \% \mathrm{Cl})$ & & 359 & & 1872 & $100.0 \%$ & $0.67[0.25,1.82]$ & & & & \\
\hline Total events & 26 & & 338 & & & & & & & \\
\hline $\begin{array}{l}\text { Heterogeneity: } \mathrm{Tau}^{2}= \\
\text { Test for overall effect }\end{array}$ & $\begin{array}{l}.66 ; \mathrm{Chi}^{2} \\
=0.78(\mathrm{r}\end{array}$ & $\begin{array}{l}=10.23 \\
P=0.44\end{array}$ & 3. $d f=4$ ( & $P=0.0$ & $04) ; 1^{2}=6$ & & 0.05 & $\begin{array}{l}0.2 \\
\text { Favors TA }\end{array}$ & ${ }^{1}$ Favors SA & 20 \\
\hline
\end{tabular}

\section{B: In-Hospital Mortality, Propensity Score-Matched Patients}

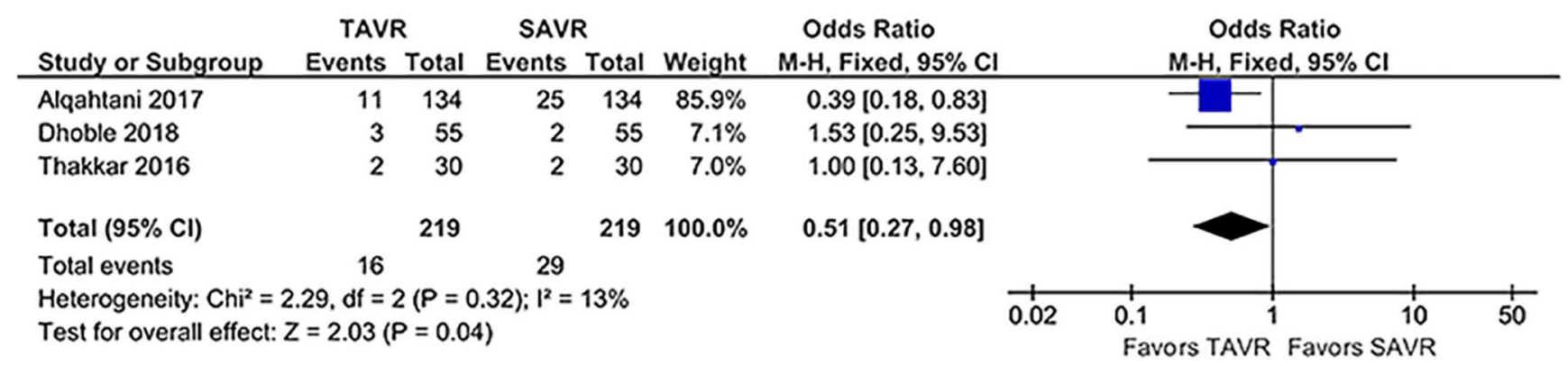

Figure 2. Comparison of in-hospital mortality in (A) all patients with chronic liver disease who underwent transcatheter aortic valve replacement (TAVR) vs those who underwent surgical aortic valve replacement (SAVR) and in (B) propensity scorematched patients. $\mathrm{Cl}$, confidence interval; df, degrees of freedom; $\mathrm{M}-\mathrm{H}$, Mantel-Haenszel.

a metaanalysis on bleeding events. Most studies, however, reported blood transfusion, and those data were pooled for reporting.

In the assessment using the ROBINS-I tool, 4 studies had a moderate risk of bias, ${ }^{2,4,15,17}$ and 1 study had an unclear risk of bias because of limited information. ${ }^{16}$

Four studies included patients with a diagnosis of liver cirrhosis undergoing either TAVR or isolated SAVR for aortic stenosis. ${ }^{2,4,15,17}$ The studies excluded patients $<50$ years of age, those with incomplete records, and patients who concomitantly underwent other cardiac procedures such as valve replacement or coronary artery bypass surgery. The study by Schill et al included patients with liver disease as defined by the STS criteria (cirrhosis, viral hepatitis, portal hypertension, alcohol dependence, or congestive hepatopathy). ${ }^{16}$

\section{Outcomes}

Overall, patients undergoing TAVR had a statistically insignificant lower rate of in-hospital mortality $(7.2 \%$ vs 18.1\%; OR 0.67; 95\% Cl 0.25, 1.82; $P=0.44 ; I^{2}=61 \%$ ) compared to the SAVR group (Figure 2A). However, propensity score matching showed significantly lower rates of in-hospital mortality in the TAVR group than the SAVR group (7.3\% vs $13.2 \%$; OR $0.51 ; 95 \% \mathrm{Cl} 0.27,0.98 ; P=0.04$; $\mathrm{I}^{2}=13 \%$ ) (Figure 2B).

The other outcomes are reported only for the propensity score-matched cohorts. Compared with SAVR patients, TAVR patients had a lower rate of blood transfusion
(51.1\% vs 27.4\%; OR 0.36; 95\% Cl 0.21, 0.60; $P<0.0001$; $\mathrm{I}^{2}=31 \%$ ) (Figure $3 \mathrm{~A}$ ) and lower mean periprocedural length of hospital stay (15.7 vs 10.9 days; mean difference -6.32 ; $95 \% \mathrm{Cl}-10.28,-2.36 ; P=0.002 ; I^{2}=83 \%$ ) (Figure 3B).

No significant differences were seen between the TAVR and SAVR groups in the proportion of patients discharged home $(65.3 \%$ vs $53.9 \%$; OR $1.3 ; 95 \% \mathrm{Cl} \mathrm{0.56,3.05;}$ $P=0.54 ; I^{2}=67 \%$ ) (Figure 3C), development of acute kidney injury $(10.4 \%$ vs $17.1 \%$; OR $0.55 ; 95 \% \mathrm{Cl} 0.29,1.07$; $P=0.08 ; 1^{2}=0 \%$ ) (Figure 3D), or mean cost of hospitalization ( $\$ 250,386$ vs $\$ 257,464$; standardized mean difference -0.07 ; $95 \% \mathrm{Cl}-0.29,0.14 ; P=0.51 ; I^{2}=0 \%$ ) (Figure 4).

\section{DISCUSSION}

In this systematic review and metaanalysis, we pooled data comparing clinical outcomes of patients with chronic liver disease undergoing TAVR and SAVR. In the propensity score-matched cohorts, we found significantly lower pooled odds of in-hospital mortality, blood transfusion, and periprocedural hospital length of stay in patients receiving TAVR, and no difference in the proportion of patients discharged home, the cost of hospitalization following the index procedure, and acute kidney injury between the 2 interventions.

Ample data elucidate the risk of cardiac surgery, including SAVR, in patients with chronic liver disease. ${ }^{18-21}$ However, little data are available comparing TAVR and SAVR in

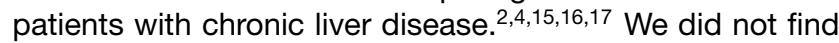
a systematic review and metaanalysis on this topic in our literature search. The available studies have small sample 
Ndunda, $P$

\section{A. Transfusion}

\begin{tabular}{|c|c|c|c|c|c|c|c|c|c|c|}
\hline \multirow{2}{*}{$\begin{array}{l}\text { Study or Subgroup } \\
\text { Alqahtani } 2017\end{array}$} & \multicolumn{2}{|c|}{ TAVR } & \multicolumn{2}{|c|}{ SAVR } & Weight & $\begin{array}{c}\text { Odds Ratio } \\
\text { M-H, Random, } 95 \% \mathrm{Cl}\end{array}$ & & \multicolumn{2}{|c|}{$\begin{array}{c}\text { Odds Ratio } \\
\text { M-H, Random, } 95 \% \mathrm{Cl}\end{array}$} & \\
\hline & 35 & 134 & 63 & 134 & $51.1 \%$ & $0.40[0.24,0.67]$ & & -1 & & \\
\hline Dhoble 2018 & 12 & 55 & 32 & 55 & $28.2 \%$ & $0.20[0.09,0.46]$ & & & & \\
\hline Thakkar 2016 & 13 & 30 & 17 & 30 & $20.7 \%$ & $0.58[0.21,1.62]$ & & & & \\
\hline Total $(95 \% \mathrm{Cl})$ & & 219 & & 219 & $100.0 \%$ & $0.36[0.21,0.60]$ & & & & \\
\hline Total events & 60 & & 112 & & & & & & & \\
\hline $\begin{array}{l}\text { Heterogeneity: } \mathrm{Tau}^{2}= \\
\text { Test for overall effect: }\end{array}$ & $\begin{array}{l}.07 ; \mathrm{Chi}^{2} \\
=3.89(\mathrm{~F}\end{array}$ & $\begin{array}{l}=2.90 \\
P=0.0\end{array}$ & $\begin{array}{l}d f=2(F \\
001)\end{array}$ & $=0.23$ & $;\left.\right|^{2}=31 \%$ & & 0.01 & 0.1 & 10 & 100 \\
\hline
\end{tabular}

\section{B. Length of Stay}

\begin{tabular}{|c|c|c|c|c|c|c|c|c|c|c|c|c|c|}
\hline \multirow[b]{2}{*}{ Study or Subgroup } & \multicolumn{3}{|c|}{ TAVR } & \multicolumn{3}{|c|}{ SAVR } & & \multirow{2}{*}{$\begin{array}{l}\text { Mean Difference } \\
\text { IV, Random, } 95 \% \mathrm{CI}\end{array}$} & \multirow{2}{*}{\multicolumn{5}{|c|}{$\begin{array}{l}\text { Mean Difference } \\
\text { IV, Random, } 95 \% \mathrm{Cl}\end{array}$}} \\
\hline & Mean & SD & Total & Mean & SD & Total & Weight & & & & & & \\
\hline Alqahtani 2017 & 12 & 13 & 134 & 16 & 13 & 134 & $43.2 \%$ & $-4.00[-7.11,-0.89]$ & & & & & \\
\hline Thakkar 2016 & 6.18 & 0.85 & 30 & 14.26 & 2.62 & 30 & $56.8 \%$ & $-8.08[-9.07,-7.09]$ & & & & & \\
\hline Total $(95 \% \mathrm{Cl})$ & & & 164 & & & 164 & $100.0 \%$ & $-6.32[-10.28,-2.36]$ & & & & & \\
\hline \multicolumn{9}{|c|}{$\begin{array}{l}\text { Heterogeneity: } \mathrm{Tau}^{2}=6.94 ; \mathrm{Chi}^{2}=6.00, \mathrm{df}= \\
\text { Test for overall effect: } Z=3.13(P=0.002)\end{array}$} & -10 & -5 & 0 & 5 & 10 \\
\hline
\end{tabular}

Figure 3. Comparison of (A) need for blood transfusion and (B) periprocedural length of stay in propensity score-matched patients with chronic liver disease who underwent transcatheter aortic valve replacement (TAVR) vs those who underwent surgical aortic valve replacement (SAVR). Cl, confidence interval; df, degrees of freedom; IV, inverse variance; $\mathrm{M}-\mathrm{H}$, Mantel-Haenszel.

sizes after propensity score matching; therefore, pooling data increased the power, and we were able to detect a difference in some outcomes between the 2 interventions.

In a study by Steffen et al, SAVR was associated with a $>3$-fold increase in in-hospital mortality in liver cirrhosis compared with patients without cirrhosis (16\% vs $5 \%$, $P<0.0001){ }^{22}$ Patients with cirrhosis also had a higher rate of any complication ( $55 \%$ vs $45 \%, P=0.0012)$ and a higher rate of acute renal failure ( $26 \%$ vs $14 \%, P<0.0001) .{ }^{22}$ Other studies corroborate these findings, showing worse outcomes in patients with cirrhosis after cardiac surgery. ${ }^{18,19}$

A study by Tirado-Conte comparing TAVR in patients with and without cirrhosis showed no difference in in-hospital and 30-day mortality, stroke, major vascular complications, bleeding complications, and new pacemaker implantation. ${ }^{23}$ However, patients with cirrhosis had a higher rate of acute kidney injury. ${ }^{23}$ In an analysis of the 2-year outcomes of the PARTNER (Placement of AoRTic TraNscathetER Valve) trial, the presence of liver disease was predictive of mortality in patients undergoing SAVR but not TAVR. ${ }^{24}$

Patients with cirrhosis have pathophysiologic states that predispose them to surgical complications. ${ }^{2,19}$ These patients are more prone to bleeding, fluid and electrolyte imbalance, infection, and organ failure such as hepatic encephalopathy, hepatorenal syndrome, and liver failure. ${ }^{2,19}$ Evidence indicates that extracorporeal circulation leads to an increase in the production of vasoactive substances and cytotoxins that interfere with coagulation, vascular resistance and permeability, the immune system, and other organ functions. ${ }^{21}$ A study by Hayashida et al suggested a benefit in avoiding extracorporeal circulation in patients with cirrhosis undergoing cardiac surgery. ${ }^{20}$ A study by Marui et al showed 3-fold lower mortality on off-pump coronary artery bypass graft surgery compared to on-pump surgery in patients with cirrhosis, even though the difference did not reach statistical significance $(P=0.29) .{ }^{1}$ This underlying pathophysiology of extracorporeal circulation during SAVR in patients with liver disease and the less-invasive nature of TAVR might explain the better outcomes suggested by this metaanalysis. The lack of a significant difference between TAVR and SAVR for the proportion of patients discharged home, cost of hospitalization, and acute kidney injury might be related to low power attributable to the small size of the metaanalysis. Furthermore, outcomes of TAVR prior to 2014 were worse than they are currently, so powered contemporary studies may find a difference between the 2 interventions in the outcomes for which this metaanalysis did not find significant differences.

Cardiac surgical risk prediction scores do not include liver disease in the risk stratification and therefore may be inadequate for evaluating patients with chronic liver disease. Studies have evaluated prognostic factors in patients with chronic liver disease undergoing cardiac surgery. ${ }^{18,25}$ Thielmann et al reported that the Model for End-Stage Liver Disease (MELD) score was the most reliable predictor of mortality in patients with cirrhosis undergoing open heart surgery compared with Child-Pugh score and EuroSCORE. ${ }^{25}$ Arif et al identified MELD score and EuroSCORE as predictive of 30-day mortality in patients with cirrhosis undergoing cardiac surgery with extracorporeal circulation. ${ }^{18}$ Arai et al compared the different risk prediction tools in patients with liver disease undergoing TAVR and reported that the Model for End-Stage Liver Disease eXcluding International Normalized Ratio (MELD-XI) score more accurately predicted 6-month mortality after TAVR (area under the receiver operating characteristic curve $=0.67$ ) compared with the STS score, EuroSCORE, and EuroSCORE II (area under the curve $=0.60$, 0.58 , and 0.57 respectively). ${ }^{26}$ 


\section{A. Patients Discharged Home}

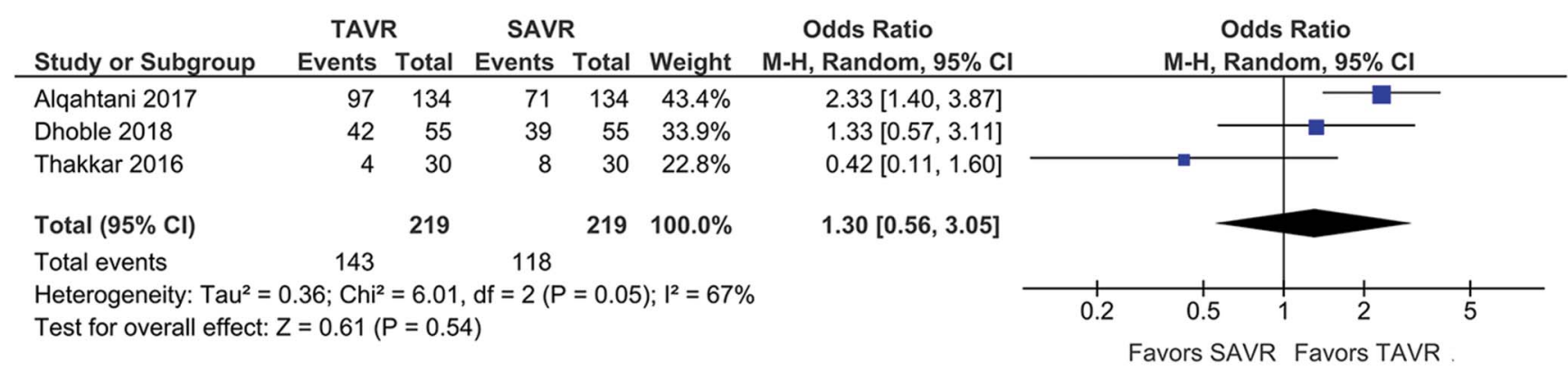

\section{B. Acute Kidney Injury}

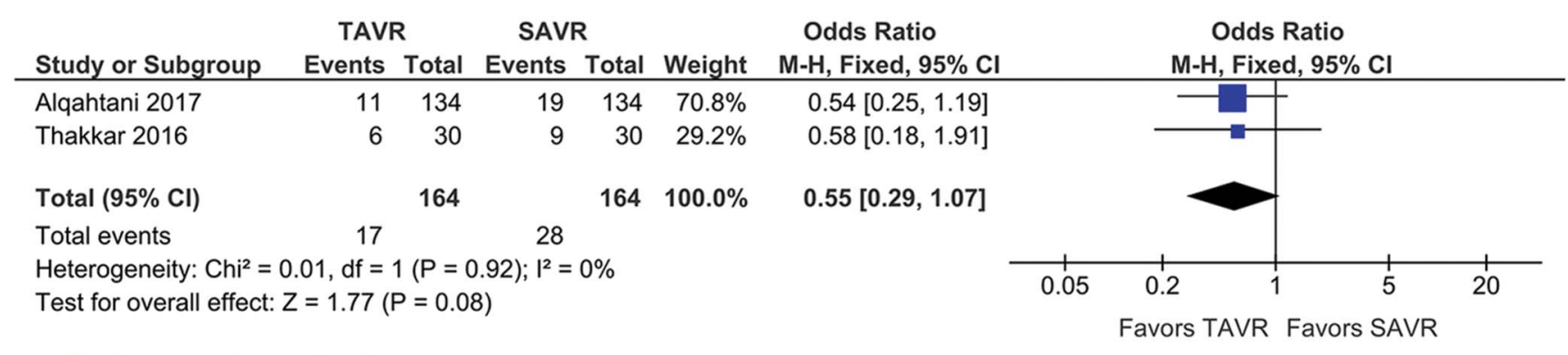

\section{Cost of Hospitalization}

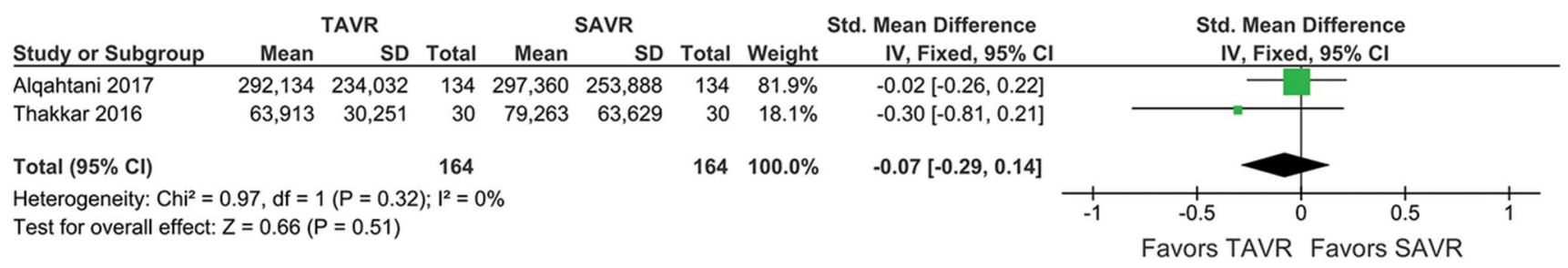

Figure 4. Comparison of (A) proportion of patients discharged home, (B) patients who developed acute kidney injury, and (C) mean cost of hospitalization in propensity score-matched patients with chronic liver disease who underwent transcatheter aortic valve replacement (TAVR) vs those who underwent surgical aortic valve replacement (SAVR). $\mathrm{Cl}$, confidence interval; df, degrees of freedom; IV, inverse variance; $\mathrm{M}-\mathrm{H}$, Mantel-Haenszel.

Our metaanalysis has limitations. Three of the included studies were based on National Inpatient Sample data that are derived from administrative data and therefore have the limitations of such a database..$^{4,15,17}$ Serum bilirubin, MELD scores, or Child-Pugh stages that would measure the severity of liver disease were not available for these 3 studies because the database did not include that data. Also, studies were limited to in-hospital outcomes. Many of the TAVR patients included in our analysis had the procedure done between 2003-2014, so findings may not reflect current procedural outcomes. TAVR valves have improved significantly since then, with smaller sheath sizes leading to lower vascular complications, improved pacemaker rate, and decreased length of stay with the newer generation devices. These improvements have led to significant improvement in the cost effectiveness of TAVR in patients with higher risk profiles. Also, the study by Schill is a conference abstract, so the data may be preliminary. ${ }^{16}$ Despite pooling data from these studies, the sample size remained low.

\section{CONCLUSION}

This analysis suggests that in patients with chronic liver disease and severe aortic stenosis, TAVR is associated with lower rates of in-hospital mortality, blood transfusion, and shorter length of hospital stay compared to SAVR. There may not be a difference in the proportion of patients discharged home, hospitalization costs, and acute kidney injury between the 2 interventions.

\section{ACKNOWLEDGMENTS}

The authors have no financial or proprietary interest in the subject matter of this article.

\section{REFERENCES}

1. Marui A, Kimura T, Tanaka S, et al; CREDO-Kyoto Investigators. Coronary revascularization in patients with liver cirrhosis. Ann Thorac Surg. 2011 May;91(5):1393-1399. doi: 10.1016/j.athoracsur.2011.01.022. 
2. Greason $\mathrm{KL}$, Mathew V, Wiesner RH, Suri RM, Rihal CS. Transcatheter aortic valve replacement in patients with cirrhosis. J Card Surg. 2013 Sep;28(5):492-495. doi: $10.1111 /$ jocs. 12177.

3. Jacob KA, Hjortnaes J, Kranenburg G, de Heer F, Kluin J. Mortality after cardiac surgery in patients with liver cirrhosis classified by the Child-Pugh score. Interact Cardiovasc Thorac Surg. 2015 Apr;20(4):520-530. doi: 10.1093/icvts/ivu438.

4. Dhoble A, Bhise V, Nevah Ml, et al. Outcomes and readmissions after transcatheter and surgical aortic valve replacement in patients with cirrhosis: a propensity matched analysis. Catheter Cardiovasc Interv. 2018 Jan 1;91(1):90-96. doi: $10.1002 / c c d .27232$.

5. Leon MB, Smith CR, Mack M, et al; PARTNER Trial Investigators. Transcatheter aortic-valve implantation for aortic stenosis in patients who cannot undergo surgery. N Engl J Med. $2010 \mathrm{Oct}$ 21;363(17):1597-1607. doi: 10.1056/NEJMoa1008232.

6. Mack MJ, Brennan JM, Brindis R, et al; STS/ACC TVT Registry. Outcomes following transcatheter aortic valve replacement in the United States. JAMA. 2013 Nov 20;310(19):2069-2077. doi: 10.1001/jama.2013.282043.

7. Popma JJ, Adams DH, Reardon MJ, et al; CoreValve United States Clinical Investigators. Transcatheter aortic valve replacement using a self-expanding bioprosthesis in patients with severe aortic stenosis at extreme risk for surgery. J Am Coll Cardiol. 2014 May 20;63(19):1972-1981. doi: 10.1016/j.jacc.2014.02.556.

8. Smith CR, Leon MB, Mack MJ, et al; PARTNER Trial Investigators. Transcatheter versus surgical aortic-valve replacement in high-risk patients. N Engl J Med. 2011 Jun 9;364(23):2187-2198. doi: 10.1056/NEJMoa1103510.

9. Kanwal F, Hoang T, Kramer JR, et al. Increasing prevalence of $\mathrm{HCC}$ and cirrhosis in patients with chronic hepatitis $\mathrm{C}$ virus infection. Gastroenterology. 2011 Apr;140(4):1182-1188.e1. doi: 10.1053/j.gastro.2010.12.032.

10. Nashef SA, Roques F, Michel P, Gauducheau E, Lemeshow S, Salamon R. European system for cardiac operative risk evaluation (EuroSCORE). Eur J Cardiothorac Surg. 1999 Jul;16(1):9-13.

11. Nashef SA, Roques F, Sharples LD, et al. EuroSCORE II. Eur J Cardiothorac Surg. 2012 Apr;41(4):734-744; discussion 744-735. doi: 10.1093/ejcts/ezs043.

12. Online STS Adult Cardiac Surgery Risk Calculator. The Society of Thoracic Surgeons. http://riskcalc.sts.org/stswebriskcalc/\#/calculate. Accessed June 27, 2019.

13. Moher D, Liberati A, Tetzlaff J, Altman DG; PRISMA Group. Preferred reporting items for systematic reviews and meta-analyses: the PRISMA statement. Ann Intern Med. 2009 Aug 18;151(4):264-269, W64.

14. Sterne JA, Hernán MA, Reeves BC, et al. ROBINS-I: a tool for assessing risk of bias in non-randomised studies of interventions. BMJ. 2016 Oct 12;355:i4919. doi: $10.1136 / \mathrm{bmj} .14919$.
15. Alqahtani F, Aljohani S, Ghabra A, et al. Outcomes of transcatheter versus surgical aortic valve implantation for aortic stenosis in patients with hepatic cirrhosis. Am J Cardiol. 2017 Oct 1;120(7):1193-1197. doi: 10.1016/j.amjcard.2017.06.067.

16. Schill MR, Henn MC, Schuessler RB, Maniar HS, Moon MR, Damiano RJ, Jr. Outcomes after minimally invasive aortic valve replacement in patients with liver disease. $17^{\text {th }}$ International Society for Minimally Invasive Cardiothoracic Surgery. http://meetings.ismics.org/abstracts/2017/P84.cgi. Published 2017. Accessed June 27, 2019.

17. Thakkar B, Patel A, Mohamad B, et al. Transcatheter aortic valve replacement versus surgical aortic valve replacement in patients with cirrhosis. Catheter Cardiovasc Interv. 2016 Apr;87(5):955-962. doi: 10.1002/ccd.26345.

18. Arif R, Seppelt P, Schwill S, et al. Predictive risk factors for patients with cirrhosis undergoing heart surgery. Ann Thorac Surg. 2012 Dec;94(6):1947-1952. doi: 10.1016/j.athoracsur.2012.06.057.

19. Gundling F, Seidl H, Gansera L, et al. Early and late outcomes of cardiac operations in patients with cirrhosis: a retrospective survival-rate analysis of 47 patients over 8 years. Eur J Gastroenterol Hepatol. 2010 Dec;22(12):1466-1473.

20. Hayashida N, Shoujima T, Teshima H, et al. Clinical outcome after cardiac operations in patients with cirrhosis. Ann Thorac Surg. 2004 Feb;77(2):500-505.

21. Paparella D, Yau TM, Young E. Cardiopulmonary bypass induced inflammation: pathophysiology and treatment. An update. Eur J Cardiothorac Surg. 2002 Feb;21(2):232-244.

22. Steffen RJ, Bakaeen FG, Vargo PR, et al. Impact of cirrhosis in patients who underwent surgical aortic valve replacement. Am J Cardiol. 2017 Aug 15;120(4):648-654. doi: 10.1016/j.amjcard.2017.05.034.

23. Tirado-Conte $\mathrm{G}$, Rodés-Cabau J, Rodríguez-Olivares $\mathrm{R}$, et al. Clinical outcomes and prognosis markers of patients with liver disease undergoing transcatheter aortic valve replacement: a propensity score-matched analysis. Circ Cardiovasc Interv. 2018 Mar;11(3):e005727. doi: 10.1161/CIRCINTERVENTIONS.117.005727.

24. Kapadia SR, Leon MB, Makkar RR, et al; PARTNER trial investigators. 5-year outcomes of transcatheter aortic valve replacement compared with standard treatment for patients with inoperable aortic stenosis (PARTNER 1): a randomised controlled trial. Lancet. 2015 Jun 20;385(9986):2485-2491. doi: 10.1016/S0140-6736(15)60290-2.

25. Thielmann $M$, Mechmet $A$, Neuhäuser $M$, et al. Risk prediction and outcomes in patients with liver cirrhosis undergoing open-heart surgery. Eur J Cardiothorac Surg. 2010 Nov;38(5):592-599. doi: 10.1016/j.ejcts.2010.02.042.

26. Arai T, Yashima F, Yanagisawa R, et al; OCEAN-TAVI investigators. Prognostic value of liver dysfunction assessed by MELD-XI scoring system in patients undergoing transcatheter aortic valve implantation. Int J Cardiol. 2017 Feb 1;228:648-653. doi: 10.1016/j.ijcard.2016.11.096.

This article meets the Accreditation Council for Graduate Medical Education and the American Board of Medical Specialties Maintenance of Certification competencies for Patient Care, Medical Knowledge, and Practice-Based Learning and Improvement. 